\title{
An unusual case of multiple endocrine neoplasia type 1 and the role of ${ }^{111}$ In-pentetreotide scintigraphy
}

\author{
H.H. Ponssen ${ }^{\text {a. } *}$, W.W. de Herder ${ }^{\text {a }}$, H.J. Bonjer ${ }^{\text {b }}$, C.C.A.P. Wauters ${ }^{c}$, \\ E.P. Krenning ${ }^{\mathrm{d}}$, S.W.J. Lamberts ${ }^{\mathrm{a}}$ \\ 'Department of Internal Medicine 3, University Hospital Rotterdam, Rotterdam, Netherlands \\ ${ }^{\mathrm{b}}$ department of Surgery, University Hospital Rotterdam, Rotterdam, Netherlands \\ ' Department of Pathology, University Hospital Rotterdam, Ratterdam, Netherlands \\ ${ }^{d}$ Department of Nuclear Medicine, University Hospital Rotterdam, Rotterdam, Netherlands \\ Received 24 November 1995; revised 7 March 1996; accepted 20 March 1996
}

\begin{abstract}
A 50-year-old woman is described with a very unusual combination of MEN-1 syndrome with a negative family history. At first she had been treated because of a clinically non-functioning pituitary adenoma in the maxillary sinus. Six years later a carcinoid tumour was discovered by means of ${ }^{111}$ In-pentreotide scintigraphy.
\end{abstract}

Keywords: Multiple endocrine neoplasia; Carcinoid tumour; ${ }^{111}$ In-pentetreotide scintigraphy

\section{Introduction}

Carcinoid tumours may be part of the multiple endocrine neoplasia (MEN) syndromes 1 and 2, although more common in MEN-1 [1]. Parathyroid adenomas are the most common feature of MEN-1 [2]. Carcinoids, hormone-secreting pancreatic isletcell tumours, pituitary adenomas, of which $13 \%$ are hormonally inactive, and adrenocortical tumours can also be part of the syndrome [3]. We describe a 50-year-old woman with a carcinoid tumour of the caecum who had been previously treated for a clinically non-functioning pituitary adenoma in the maxillary sinus (Ref. [4], patient 6).

\footnotetext{
${ }^{*}$ Corresponding author, present address: Department of Intensive Care, St. Radboud Ziekenhuis, PO Box 9101, 6500 HB, Nijinegen, Netherlands.
}

\section{Case report}

A 50-year-old caucasian female presented to our department because of pain in the right lower abdominal quadrant and loss of appetite. In the last 4 months, she had lost $3 \mathrm{~kg}$ weight and had suffered attacks of diarrhoea once a week. In the last weeks before admission the pain increased and she developed complaints of nausea and sometimes she had to vomit. There were no complaints of flushing or shortness of breath. An appendectomy had been performed 24 years before. Her family history was negative for endocrine tumours.

Six years before admission she underwent an operation of the left maxillary sinus because of a tumour. At first this tumour was diagnosed as an aesthesioneuroblastoma, and she underwent locally applied chemotherapy and external radiation therapy. 


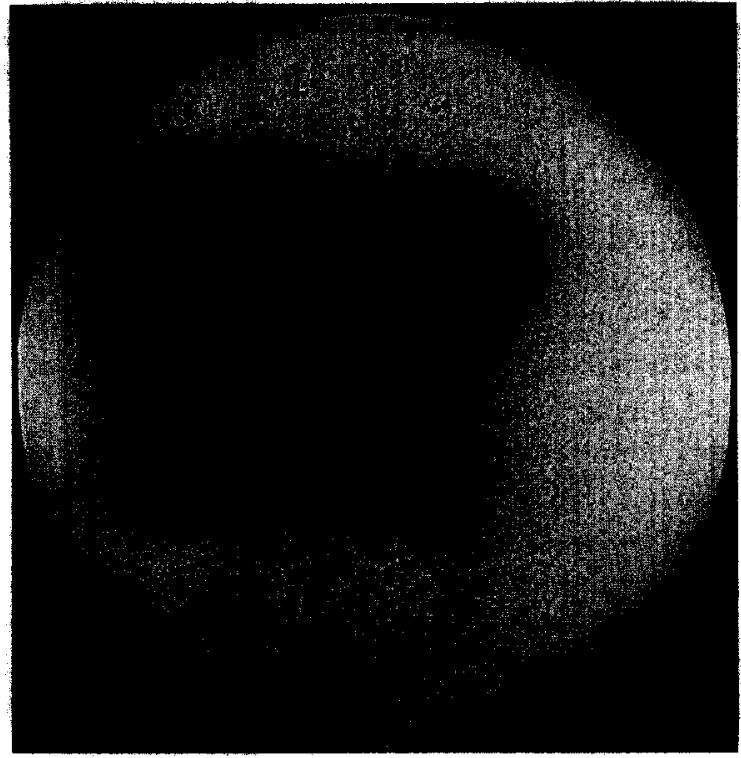

Fig. 1. ${ }^{111}$ In-pentetreotide (OctreoScan) image in the anterior plane obtained $96 \mathrm{~h}$ after injection. Physiological uptake in the liver, spleen and kidneys is shown. Note area of increased uptake in the right lower abdominal quadrant (arrow). Some activity is also present in the bowel.

Revision of the tumour pathology showed that it was a clinically non-functioning 'ectopic' pituitary adenoma. A postoperative CT-scan showed normal bony sellar margins while the anterior pituitary function had remained normal. [4]

Four years before admission she had also visited our department because of abdominal pain and vomiting. Standard radiographs of the abdomen showed a few air-fluid levels which disappeared after conservative treatment. Colonoscopy (by which the terminal ileum could be reached), a small-bowel followthrough examination and computer tomography (CT) of the abdomen showed no abnormalities. An ${ }^{111} \mathrm{In}$ pentetreotide scintigram (OctreoScan, Malinckrodt, Petten, Netherlands), which was performed as part of a study of pituitary tumours, showed unexpectedly a 'hot spot' in the right lower quadrant of the abdomen. 5-Hydroxyindole acetic acid (5-HIAA) excretion in the urine was within normal limits. The patient recovered spontaneously at that time and had been regularly followed in our outpatient clinic.

At the present hospital admission the patient appeared well. On physical examination there was slight tenderness in the lower part of the right side of the abdomen. No masses were felt. There were no signs of right-sided heart failure.

Routine laboratory results showed no abnormalities. Serum calcium amounted to $2.40 \mathrm{mmol} / 1$, albumen $46 \mathrm{~g} / 1$ and PTH(1-84) $14.9 \mathrm{ng} / \mathrm{l}(\mathrm{N})$. Urinary 5-HIAA excretion varied between 28.2 and 36.6 $\mu \mathrm{mol} / 24 \mathrm{~h}$; incidentally a value of $50.9 \mu \mathrm{mol} / 24 \mathrm{~h}$

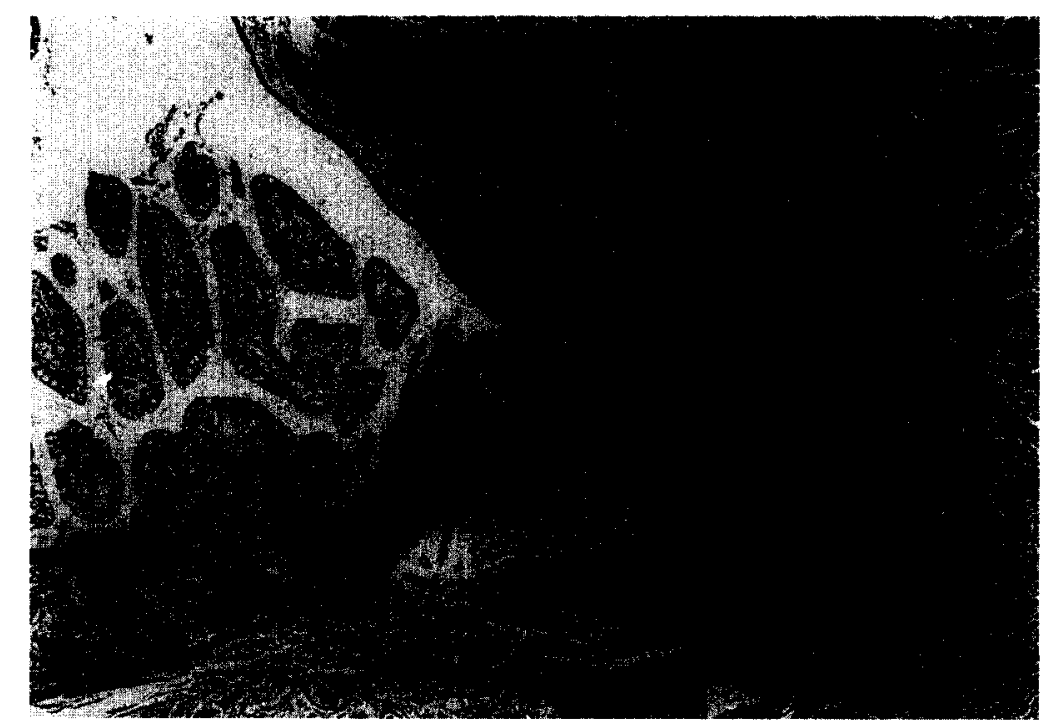

Fig. 2. Section through mucosa and submucosa of the colon. Carcinoid tumour (short arrow), normal mucosa (long arrow). Haematoxylineosin; original magnification $\times 25$. 
was obtained ( $\mathrm{N}<50 \mu \mathrm{mol} / 24 \mathrm{~h})$. Colonoscopic examination was without abnormalities, but the caecum could not be reached because it seemed to be flexed dorsally. A small-bowel follow-through showed no abnormalities. Ultrasound examination showed a normal liver and a slightly enlarged lymph-node in the painful area of the abdomen. An ultrasound-guided fine needle aspiration was performed. Cytological examination showed cohesive clusters of small neoplastic cells with round or oval nuclei, stippled nuclear chromatin and small amounts of intact cytoplasm suggestive of carcinoid tumour.

${ }^{111}$ In-pentetreotide scintigraphy was repeated, but only showed the 'hot spot' in the abdomen at exactly the same location as found 2 years previously; the liver showed no abnormalities (Fig. 1). At midline laparotomy, a small tumour with a diameter of $1 \mathrm{~cm}$ was found in the mesentery at the ileocaecal junction. A fibrotic band extending from this tumour had resolved in a stenosis of the terminal ileum. A right hemicolectomy was performed. Ultrasound examination during the operation did not show any abnormalities in the para-aortic region or in the liver.

The ascending colon revealed a submucosal elevation approximately $1 \mathrm{~cm}$ in diameter. On transection it was firm, yellow and infiltrated into the subserosal fat. Histologically, the lesion was composed of small nests and strands of epithelial cells. The cells were quite regular, with uniform round to oval nuclei and infrequent mitosis (Fig. 2). Silver impregnation techniques (Grimelius staining) and immuno-histochemical staining for chromogranin and serotonin were positive.

Postoperative values for 5-HIAA excretion in the urine varied between 18.1 and $32.2 \mu \mathrm{mol} / 24 \mathrm{~h}$. An ${ }^{111}$ In-pentetreotide scan no longer showed any uptake in the abdominal region. During follow-up (2 years) signs of bowel obstruction did not recur.

\section{Discussion}

The occurrence of tumours involving two or more endocrine glands is characteristic for MEN [3,5]. Typically the MEN-1 syndrome consists of tumours of the parathyroid glands in $90 \%$ [6], of the pancreatic islet-cells in $30-75 \%$ and of the anterior pituitary in $15-90 \%$ of cases; $12 \%$ of the latter tumours are clinically non-functioning [5]. During screening 83 to $100 \%$ of the relatives become clinically or biochemically positive [5]. In this case-report we describe a patient who first presented with an 'ectopic', clinically non-functioning pituitary adenoma and developed a carcinoid tumour in the caecum several years later. The history of the family was negative for MEN-1. There was no hyperparathyroidism. At a previous admission the carcinoid tumour had not been found, even though ${ }^{11 / 1}$ Inpentetreotide scintigraphy had been positive in this region. 5-HIAA excretion in the urine was normal, probably because there was no involvement of the liver.

Episodic flushing and diarrhoea are the most common features of a carcinoid tumour. Right-sided heart failure, wheezing and pellagra may also be part of the disease [7,8]. Midgut carcinoids produce symptoms as soon as there is involvement of the liver. However, small carcinoids may also cause diarrhoea because they are able to induce mesenteric fibrosis resulting in twisting, intestinal obstruction, bacterial overgrowth, discontinuation of intestinal blood supply and mesenteric infarction [9]. Carcinoid tumours normally secrete serotonin but are also able to secrete tachykinins and substance $P[10]$. The metabolite of serotonin-5-hydroxyindole acetic acid (5-HIAA), which can be measured in the urine-is generally accepted as the diagnostic hall-mark of the carcinoid syndrome.

Gastro-entero-pancreatic tumours, carcinoids and other APUDoma's (Amine Precursor Uptake and Decarboxylation) like pituitary tumours can be successfully visualised by means of ${ }^{111}$ In-pentetreotide scintigraphy; the sensitivity of this method is $60-92 \%$ [11-15]. However, granulomas like those found in tuberculosis, sarcoidosis, Wegener's granulomatosis and lymphomas can also be visualized, making this method unsuitable for the differential diagnosis [12].

We conclude that ${ }^{111}$ In-pentetreotide scintigraphy in patients known to have pituitary tumours or primary hyperparathyroidism and complaints of the gastrointestinal tract, showing consistent areas of increased uptake of radioactivity in the abdomen, should arouse clinical suspicion of a potential localisation of an APUDoma within the spectrum of the MEN-1 syndrome. 


\section{References}

[1] Duh QY, Hybarger CP, Geist R, et al. Carcinoids associated with multiple endocrine neoplasia syndromes. Am J Surg 1987;154(1):142-148.

[2] Buchanan HD, et al. Neuroendocrine tumors, European view. Am J Med 1986;81(suppl 6B):14-20.

[3] Anonymous. Carcinoid tumours and endocrine cell hyperplasia. Lancet 1989;1-2:940 (editorial).

[4] van der Lely AJ, Knegt PPM, Stefanko SZ, Tanghe HLJ, Singh R, Lamberts SWJ. Nasopharyngeal presentation of pituitary tumors. Differential diagnosis and treatment. J Clin Endocrinol Metab 1992;74:811-813.

[5] Thakker RV, Ponder BAJ. Multiple endocrine neoplasia. Baillere's Clin Endocrinol Metab 1988;2:1031-1068.

[6] Skogseid B, Rastad J, Oberg K. Multiple endocrine neoplasia type 1. Endocrinol Metab Clin North Am 1994;23.

[7] de Herder WW, van der Lely AJ, Lamberts SWJ. Somatostatin analogue treatment of neuroendocrine tumors. Postgrad Med J 1996;in press.

[8] de Graeff A, Kooyman CD, Obertop H, Lips CJM. Carcinoide tumoren: nieuwe inzichten in biochemische en endocriene aspecten, diagnostick en behandeling. Ned Tijdschr Geneeskd 1992;136:508-513.
[9] Moertel CG. An odyssey in the land of small tumors. J Clin Oncol 1987;5:1502-1522.

[10] Kvols LK, Reubi JC. Metastatic carcinoid tumors and the malignant carcinoid syndrome. Acta Oncol 1993;32:197-201.

[11] Kwekkeboom DJ, Krenning EP, Bakker WH, Oei HY, Kooy PP, Lamberts SW. Somatostatin analogue scintigraphy in carcinoid tumors. Eur J Nucl Med 1993;20:283-292.

[12] Lamberts SWJ, Krenning EP, Reubi JC. The role of somatostatin and its analogs in the diagnosis and treatment of tumors. Endocr Rev 1991;12:450-478.

[13] Lamberts SWJ, Bakker WH, Reubi JC, Krenning EP. Treatment with sandostatin and in vivo localization of tumors with radiolabeled sanmatostatin analogs. Metabolism 1990;9:152155.

[14] Lamberts SWJ, Bakker WH, Reubi JC, Krenning EP. Somatostatin-receptor imaging in the localization of endocrine tumors. N Engl J Med 1990;323:1246-1249.

[15] Kvols LK, Brown ML, O'Connor MK, et al. Evaluation of a radiolabeled somatostatin analog (I-123 octreotide) in the detection and localization of carcinoid and islet cell tumors. Radiology 1993;187:129-133. 